\title{
Stromal-derived factor-1 $\alpha$ induces a non-canonical pathway to activate the endocrine-linked Tac1 gene in non-tumorigenic breast cells
}

\author{
Kelly E Corcoran ${ }^{1,3}$, Ashwani Malhotra ${ }^{1}$, Carlos A Molina ${ }^{2}$ and Pranela Rameshwar ${ }^{1}$ \\ ${ }^{1}$ Departments of Medicine-Hematology-Oncology and Obstetrics and Gynecology, New Jersey Medical School, University of Medicine and Dentistry of New Jersey, Newark, \\ New Jersey 07103, USA \\ ${ }^{2}$ Department of Biology and Molecular Biology, Montclair State University, Montclair, New Jersey 07043, USA \\ ${ }^{3}$ Graduate School of Biomedical Sciences, University of Medicine and Dentistry of New Jersey, Newark, New Jersey, USA \\ (Correspondence should be addressed to P Rameshwar who is now at UMDNJ-New Jersey Medical School, MSB, Rm. E-579, 185 South Orange Avenue, Newark, New Jersey 07103, \\ USA; Email: rameshwa@umdnj.edu)
}

\begin{abstract}
The chemokine Stromal-derived factor- $1 \alpha(\mathrm{SDF}-1 \alpha)$ interacts with seven transmembrane (TM) G-protein-coupled receptor (GPR), CXCR4. SDF-1 $\alpha$ is linked to inflammation, chemoattraction, cancer metastasis, and hematopoiesis. Tachykinin (Tac1) peptides bind seven transmembrane (TM), GPR and are involved in tumor promotion. SDF-1 $\alpha$ regulates Tac1 expression in non-tumorigenic breast cells through a bimodal pattern with repression at high levels through nuclear factorkappa B (NFKB) activation. This study focuses on the mechanism of activation at low SDF-1 $\alpha$ in MCF12A non-tumorigenic breast cells. Reporter gene assays with the $5^{\prime}$ flanking region of Tac1 (exon 1 omitted) and co-transfection with the repressor of cAMP response element (CREB) (ICER), and transfection with the CRE sites mutated, verified critical roles for CRE sites in SDF-1 $\alpha$-mediated Tac1 activation. Western blots and functional assays with specific inhibitors indicated that SDF-1 $\alpha$ phosphorylated CREB (P-CREB) via G $\alpha_{i} 2-\mathrm{PI} 3 \mathrm{~K}$-protein kinase C (PKC) $\zeta$-p38-extracellular signal-regulated kinase (ERK) and no evidence of CAMP-PKA pathway. This observation is different from previous studies that reported CREB-phosphorylated PKA pathway in the activation of Tac1 in bone marrow stromal cells. This suggests cell specificity in Tac1 expression. In conclusion, this study reports on a non-canonical pathway in Tac1 activation by SDF-1 $\alpha$. This finding is significant, since Tac1 is relevant to breast cancer metastasis, to bone marrow where stromal cells have a significant facilitating function.
\end{abstract}

Journal of Molecular Endocrinology (2008) 40, 113-123

\section{Introduction}

Stromal-derived factor (SDF-1), which belongs to the CXC chemokine family, functions as a chemoattractant for immune and hematopoietic cells (Ganju et al. 1998). Through alternative splicing, two SDF-1 variants are produced, $\alpha$ and $\beta$ forms (De La Luz Sierra et al. 2004). Each variant binds to the G-protein-coupled seven transmembrane CXCR4 receptor (Juarez et al. 2004). Activation by SDF- $1 \alpha$ leads to intracellular calcium mobilization and signaling linked to cell motility (Wang et al. 2000).

SDF-1 $\alpha$ levels are elevated in several organs, including the bone marrow, although its concentrations are compartmentalized (Lapidot $e$ al. 2005). SDF-1 $\alpha$ levels are relatively high close to the endosteum of bone marrow, which has been attributed to its constitutive production by the endogenous stromal cells (Kucia et al. 2005). Bone marrow shows a gradient pattern in SDF-1 $\alpha$ levels across the cavity (Jung et al. 2006). This pattern is indirectly proportional to the level of hypoxia (Ceradini et al. 2004, Jung et al. 2006). Through multiple mechanisms, SDF- $1 \alpha$ is involved in cellular movement in and out of the bone marrow toward other organs and also in the peripheral circulation (Ceradini et al. 2004, Kucia et al. 2005, Lapidot et al. 2005, Jung et al. 2006). Membrane-bound SDF-1 $\alpha$ is partly responsible for retention of cells in the bone marrow, including hematopoietic stem cells, which express its cognate receptor, CXCR4 (Gazitt 2004).

Tac1 (preprotachykinin-A) is an evolutionary conserved single copy gene that is ubiquitously expressed (Greco et al. 2004). Tac1 encodes several peptides belonging to the tachykinin family, of which substance $\mathrm{P}$ and neurokinin-A are its major products (Singh et al. 2000, Bellucci et al. 2002, Greco et al. 2004). The tachykinins interact with varying affinities to three neurokinin (NK) receptors such as NK1, NK2, and 
NK3 (Kang et al. 2004). NK receptors belong to the group of G-protein-coupled seven TM receptors (Bandari et al. 2003). In healthy cells, NK1 and NK2 exhibit intracellular crosstalk that appears to regulate the functions of each other (Kang et al. 2004).

Tac1, NK1, and NK2 are co-expressed in several cancers, including breast cancer (Singh et al. 2000, Rao et al. 2004, Bigioni et al. 2005, Jung et al. 2006). In several cases, cause-effect relationships have been demonstrated between Tac1 expression and tumorigenesis (Aalto et al. 1998, Moharita et al. 2004, Oh et al. 2004, Rao et al. 2004, Bigioni et al. 2005). In addition, experimental studies have demonstrated a facilitating role for Tac1 in the entry of breast cancer cells into bone marrow (Oh et al. 2004, Rao et al. 2004). Tac1 peptides have also been shown to mediate functions amenable to cancer development. These include protection from radiation damage, hypoxia, apoptosis, enhanced proliferation, and induction of cytokines with angiogenic functions and growth-promoting properties (Fan et al. 1993, Rameshwar \& Gascon 1996, Aalto et al. 1998, Qian et al. 2001b). These studies linking Tac1 to breast cancer are important when one considers this type of cancer as hormone dependent. In fact, we have previously shown an inductive role for two neurohormones, prolactin and adrenocorticotropin, in the expression of Tac1 and one of its receptor, neurokinin1 (Maloof et al. 2001).

SDF- $1 \alpha$ has a major role in cancer metastasis due to its chemoattractant property for CXCR4-expressing cancer cells (Muller et al. 2001). The density of CXCR4 on breast cancer cells is proportional to the invasiveness of the cancer (Kato et al. 2003, Mori et al. 2004, Smith et al. 2004). Tac1 appears to be involved in the production of SDF-1 $\alpha$ since its level is decreased in Tac1 knockdown breast cancer cells (Oh et al. 2004). The Tacl gene has been linked to stress, which has been considered as a risk for breast cancer recurrence (Palesh et al. 2007, Ziemssen \& Kern 2007). In addition, Tac1 and its receptors, NK1 and NK2, are expressed in breast cancer cells (Singh et al. 2000, Oh et al. 2004, Rao et al. 2004). Furthermore, their expressions appear to be linked to the invasiveness of the cancer cells lines (Castro et al. 2005). Thus, an understanding of the molecular pathway by which Tac1 is regulated would provide insights on the role of the endocrine-linked Tac1 to breast cancer metastasis, and perhaps relapse. We report on the mechanism by which SDF-1 $\alpha$ induces Tac1 expression in non-tumorigenic breast cells. This model has been selected to avoid confounds of multiple mutations in breast cancer cells. Using reporter gene assays with the $5^{\prime}$ flanking region of Tac1, we have identified stimulation through $\mathrm{G} \alpha_{i} 2$ activation of the MAPK cascade, but not the expected PKA phosphorylation of CRE-binding proteins (Qian et al. 2001a, Jung et al. 2006).

\section{Materials and methods}

\section{Reagents and antibodies}

FCS, anti-diphosphorylated ERK1/2, and -actin mAb were purchased from Sigma. Recombinant human (rh) SDF-1 was purchased from R\&D Systems (Minneapolis, MN, USA). Anti-PKC $\alpha$, anti-PKC $\zeta$, and horse radish peroxiase (HRP)-conjugated goat anti-murine IgG were purchased from Santa Cruz Biotechnology (Santa Cruz, CA, USA). Rabbit anti-CREB, anti-phospho-CREB, antiATF-2, HRP-conjugated goat-anti rabbit IgG, and PI3K inhibitor (LY294002) were purchased from Cell Signaling Technology (Beverly, MA, USA). Antibodies to G-proteins were purchased as a kit of multiple antiG-proteins from Biomol (Plymouth Meeting, VA, USA). cAMP inhibitor (cAMPS-Rp, triethylammonium salt) was purchased from Tocris Bioscience (Ellisville, MO, USA). PKA inhibitor (H-89), p38 inhibitor (2-(4-chlorophenyl)4-(4-fluorophenyl)-5-pyridin-4-yl-1,2-dihydropyrazol3-one), ERK inhibitor (3-(2-aminoethyl)-5-((4-ethoxyphenyl) methylene)-2,4-thiazolidinedione, $\mathrm{HCl})$, AKT inhibitor (1L-6-hydroxymethyl-chiro-inositol 2-(R)-2-Omethyl-3-O-octadecylcarbonate), and C-Jun N-terminal kinases (JNK) inhibitor (anthra [1,9-cd]pyrazol-6(2H)one 1,9-pyrazoloanthrone) were purchased from EMD Biosciences (San Diego, CA, USA). Myristoylated PKC inhibitor was purchased from Promega. Anti-PKC $\alpha$ and anti-PKC $\zeta$ were purchased from Santa Cruz Biotechnology. Anti-MEKK1 / 2 antibody was purchased from Upstate (Charlottesville, VA, USA).

\section{Cell lines}

MCF12A cells were purchased from American Type Culture Collection, ATCC (Manassas,VA, USA). The cell line was cultured according to ATCC instructions.

\section{Vectors}

pGL3-basic containing inserts of the $5^{\prime}$ flanking regions of Tacl were previously described (Qian et al. 2001a). The basic form is under the control of the inserted promoter as compared with the control promoter, which is under the control of SV40. Tac1/1.2 was previously referred to as PPT-I/1.2. The designation is changed in order to maintain consistency with the evolving consensus for referring to the family of genes, of which there are currently four members. Tac $1 / 1 \cdot 2$ includes the upstream region of intron 1, exon 1, and sequences that flank the $5^{\prime}$ region of exon 1 . The other insert, Tacl/N0 was previously referred to as PPT-I/N0. This insert represents only the upstream region of exon 1 . Mutated inserts were constructed using the site directed mutagenesis kit from Stratagene (La Jolla, CA, USA), as previously described (Qian et al. 2001a). The expression vector containing 
the ICER II- $\gamma$ coding sequence ( $\mathrm{pSV}_{2}$ ICER II- $\gamma$ ) is under the control of the SV40 promoter, which has previously been described (Qian et al. 2001a).

\section{Transfection and reporter gene assays}

MCF12A cells were transfected with Effectene reagent (Qiagen). Transfectants were stimulated with SDF-1 $\alpha$ ranging between 5 and $100 \mathrm{ng} / \mathrm{ml}$ in sera-free media. In parallel studies, MCF12A cells were co-transfected with $\mathrm{pSV}_{2}$ ICER II- $\gamma$ and PPT-I/N0, then stimulated with 20, 50 , or $100 \mathrm{ng} / \mathrm{ml} \mathrm{SDF}-1 \alpha$. In inhibitor studies, transfectants were stimulated with $50 \mathrm{ng} / \mathrm{ml}$ SDF- $1 \alpha$ in the presence or absence of cAMP, PKA, AKT, LY294002, PKC, JNK, ERK, or MAPK (p38) inhibitors. After $16 \mathrm{~h}$, cells were collected in $30 \mu \mathrm{l}$ lysis buffer (Promega) and then subjected to freeze-thaw cycles in a dry ice/ethanol bath. Cell-free lysates were obtained by centrifugation at $4000 \mathrm{~g}$ for $5 \mathrm{~min}$ at $4{ }^{\circ} \mathrm{C}$. Luciferase activities were quantitated with the lysates using the Luciferase Assay System (Promega) and then presented as luciferase activity per microgram of total protein. The activities subtracted the luciferase background obtained with vector alone, which were $<5 \mathrm{RLU}$. Total protein was determined with a kit purchased from Bio-Rad DC protein assay method.

\section{Western analysis}

MCF12A cells were unstimulated or stimulated with SDF-1 $\alpha(20,50$, or $100 \mathrm{ng} / \mathrm{ml})$. In parallel studies, MCF12A cells were stimulated with SDF- $1 \alpha(50 \mathrm{ng} / \mathrm{ml})$ and/or the PI-3K inhibitor LY294002 $(50 \mu \mathrm{M})$ or pertussis toxin $(100 \mathrm{ng} / \mathrm{ml})$. After $1 \mathrm{~h}$, nuclear proteins were extracted using the N-extract kit (Sigma) and the total protein concentrations were determined as described above. Extracts $(15 \mu \mathrm{g})$ were analyzed by western blots using 12\% SDS-PAGE, and the proteins were transferred onto polyvinylidene difluoride membranes (Perkin-Elmer Life Sciences, Boston, MA, USA). The membranes were incubated overnight with primary antibody. Except for anti-actin, rabbit was the source of all primary antibodies. Primary antibodies were detected by 2-h incubation with HRP-conjugated IgG. All primary and secondary antibodies were used at final dilutions of $1 / 1000$ and $1 / 2000$ respectively. HRP was developed with chemiluminescence detection reagent (Perkin-Elmer Life Sciences).

\section{Data analyses}

Statistical evaluations of the data were done with ANOVA and Tukey-Kramer multiple comparisons test. A value of $P<0.05$ was considered significant.

\section{Results}

The effects of SDF-1 $\alpha$ on Tac1 expression follow a bellshaped pattern with high levels repressing its activity through NFKB activation and low levels activating its expression (Corcoran et al. 2007). The repression of Tac1 activity at high SDF-1 $\alpha$ concentration by NFKB activation involves the untranslated exon 1 (Corcoran \& Rameshwar 2007). An understanding of SDF- $1 \alpha$-mediated stimulation of Tac1 requires studies that omit exon 1. This was addressed with a reporter gene construct with $740 \mathrm{bp}$ upstream of exon 1, Tac1/N0 (Qian et al. 2001a). This region has two CRE-binding sites that have previously been reported to activate Tacl (Qian et al. 2001a). It is also possible that the CRE-binding sites might be responsive to downstream events by G-protein activation linked to CXCR4 (Roland et al. 2003).

\section{ICER in Tac1/NO activation}

The first set of studies focused on reporter gene activity by Tac1/N0 in which we blunted the CRE-binding sites with the negative regulator of CRE sites, early inducible cAMP repressor, ICER (Rosenberg et al. 2002, Servillo et al. 2002). MCF12A cells were co-transfected with pGL3-Tac1/N0 and $\mathrm{pSV}_{2}$ ICER II- $\gamma$, an ICER expression vector, which negatively regulate activators of CRE-binding proteins (Rosenberg et al. 2002, Servillo et al. 2002). Transfectants were stimulated with concentration ranges of SDF-1 $\alpha$ that have been shown to exhibit activation effects on endogenous Tac1 expressions, and reporter gene activity in the presence of exon 1 (20 and $50 \mathrm{ng} / \mathrm{ml}$; Corcoran \& Rameshwar 2007). To compare the stimulatory effects, we performed parallel studies with one concentration that inhibited endogenous Tac1 expression, including reporter gene activity when exon $1(100 \mathrm{ng} / \mathrm{ml})$ was present (Corcoran \& Rameshwar 2007). Controls included unstimulated transfectants or cells transfected with pGL3 alone. As expected (Corcoran \& Rameshwar 2007), there were dose-dependent effects between luciferase activities and SDF-1 $\alpha$ levels (Fig. 1A, hatched bars). However, in transfectants with $\mathrm{pSV}_{2} \mathrm{ICER}$ II- $\gamma$, there was significant $(P<0 \cdot 05)$ reduction in luciferase activities (Fig. 1A, open bars). The results showed negative effects of $\mathrm{pSV}_{2}$ ICER II- $\gamma$ on the activation of Tac1/N0.

\section{Effects of CRE-binding sites on the activation of PPT-I/NO by SDF-1 $\alpha$}

The next set of studies sought to determine whether one or both CRE sites were involved in SDF-1 $\alpha$-mediated activation of PPT-I/N0. We therefore transfected MCF12A with Tac1/N0 wild type or mutated at the first, second, or both CRE sites (CRE-Mut I, CRE-Mut II, or CRE-Mut I and II). The effectiveness of mutation was 

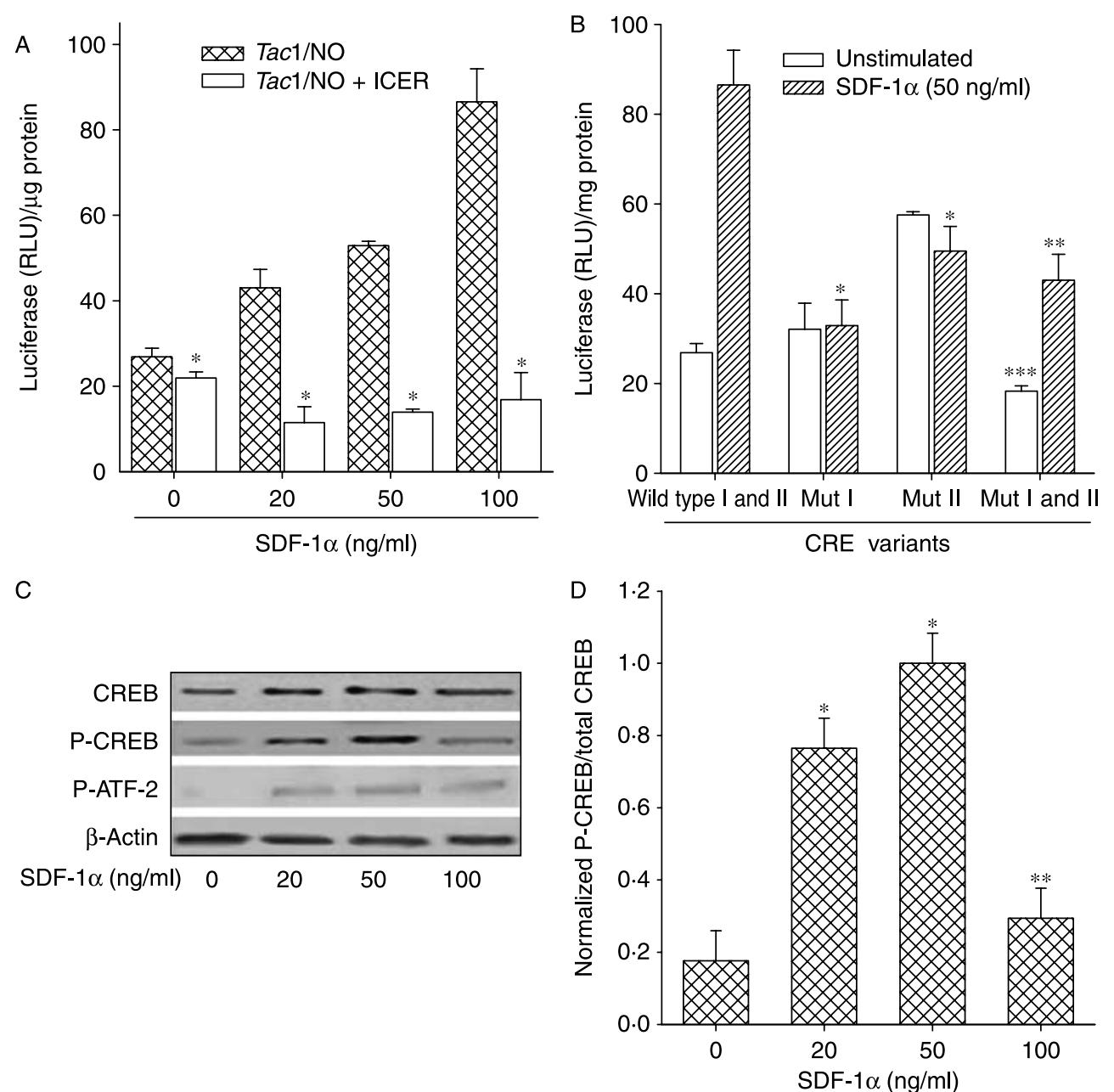

Figure 1 Role of CRE-binding sites in SDF-1 $\alpha$-mediated activation of PPT-I/NO. (A) MCF12A was transfected with $\mathrm{pGL} 3 / \mathrm{Tac} 1 / \mathrm{NO}$ and/or $\mathrm{pSV}_{2}$ ICER II- $\gamma$. After $24 \mathrm{~h}$, transfectants were stimulated for $16 \mathrm{~h}$ with different concentrations of SDF-1 $\alpha$. Luciferase activities were determined and presented as mean $\mathrm{RLU} \pm$ s.D., $n=4 .{ }^{*} P<0.05$ versus Tac1/N0 alone. (B) MCF12A was transfected with $\mathrm{pGL3}-\mathrm{PPT}-\mathrm{I} / \mathrm{N} 0$, wildtype CRE sites; CRE-mutant I, CRE-mutant II, or CRE-mutants I and II. Transfectants were stimulated with $50 \mathrm{ng} / \mathrm{ml}$ SDF- $1 \alpha$. The results are presented as mean RLU \pm s.D., $n=5$. (C) MCF12A cells were unstimulated or stimulated with SDF- $1 \alpha(20,50$, or $100 \mathrm{ng} / \mathrm{ml})$. After $1 \mathrm{~h}$, whole cell extracts were analyzed by western blots with anti-P-CREB. Membranes were stripped and reprobed consecutively with anti-CREB, anti-P-ATF-2, and $\beta$-actin. Representative blots are shown for four different experiments. (D) The CREB and $\mathrm{P}$-CREB bands were normalized with $\beta$-actin and then presented as the fraction of total P-CREB/total CREB (mean \pm s.D., $n=4$ ). ${ }^{\star} P<0.05$ versus transfectants without ICER.

previously reported by gel shift assays (Qian et al. 2001a). To remain focused, we selected $50 \mathrm{ng} / \mathrm{ml} \mathrm{SDF}-1 \alpha$. As expected, there was significant increase in luciferase activity for cells transfected with wild-type CRE (Fig. 1B, open bars). Single mutation at either CRE sites significantly $(P<0.05)$ reduced luciferase activities (Fig. 1B, two middle bars). However, the blunting effect was more pronounced for CRE-Mut I than CRE-Mut II (Fig. 1B). Interestingly, the stimulation of transfectants with double CRE mutations led to significant $(P<0 \cdot 05)$ increase in luciferase activities (Fig. 2B, hatched bar). These were highly significant findings that are discussed.
While single mutation of either CRE-Mut I blunted the response to SDF-1 $\alpha$, CRE-Mut II was less efficient at inhibiting the effect of SDF- $1 \alpha$.

\section{CREB activation in SDF-1 $\alpha$-stimulated MCF12A}

Based on a role for CRE-binding proteins in the activation of Tac1/N0 (Fig. 1A and B), we next confirmed that the reporter gene activity correlates with the presence of CRE-binding proteins. To address this question, we studied cell extracts for two of the major CRE-binding proteins, phospho (P)-CREB and ATF-2 (Rosenberg et al. 


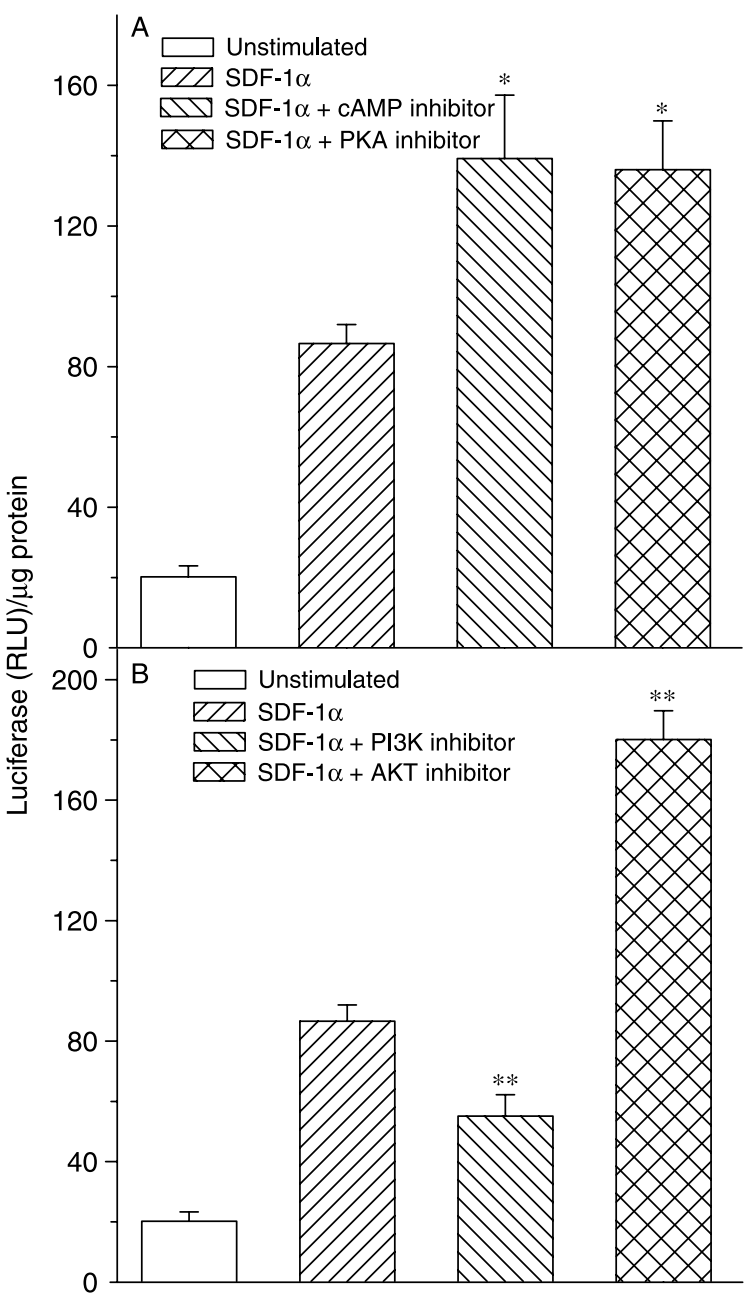

Figure 2 Intracellular pathways in the activity of Tac1/N0 in SDF-1 $\alpha$ stimulation. (A) MCF12A cells were transfected with pGL3-Tac1/N0 and the transfectants were stimulated with $50 \mathrm{ng} / \mathrm{ml} \mathrm{SDF}-1 \alpha$ in the presence or absence of cAMP or PKA inhibitor. The results are presented as mean RLU \pm s.D., $n=5$.

(B) MCF12A was transfected with pGL3-Tac1/N0. Transfectants were stimulated with $50 \mathrm{ng} / \mathrm{ml} \mathrm{SDF-1 \alpha}$ in the presence or absence of LY294002 or AKT inhibitor. The results are presented as mean $\mathrm{RLU} \pm$ s.D., $n=5$. ${ }^{*} P<0.05$ versus cultures without inhibitors. ${ }^{\star \star} P<0.05$ versus cultures without inhibitor.

2002). Extracts were obtained from MCF12A stimulated for $1 \mathrm{~h}$ with SDF- $1 \alpha$ at 20,50 , or $100 \mathrm{ng} / \mathrm{ml}$. The stimulation time was determined in time-course studies (not shown). Representative of four western blots, performed for total CREB, P-CREB, and ATF-2, shows increase in nuclear P-CREB at stimulations by 20 and $50 \mathrm{ng} / \mathrm{ml} \mathrm{SDF}-1 \alpha$, and decrease in its phosphorylation at $100 \mathrm{ng} / \mathrm{ml} \mathrm{SDF}-1 \alpha$ (Fig. 1C). Normalization was done by stripping of membranes and then reprobing with anti- $\beta$ actin (Fig. 1C, bottom row). The changes in P-CREB are presented as a fraction of normalized total CREB (Fig. 1D, $n=4)$. While SDF- $1 \alpha$ at 20 and $50 \mathrm{ng} / \mathrm{ml}$ showed four- and sixfold increase in P-CREB, at $100 \mathrm{ng} / \mathrm{ml}$ SDF$1 \alpha$, there was significant $(P<0 \cdot 05)$ decrease in P-CREB (Fig. 1D). In summary, the results show an increase in P-CREB at low levels of SDF- $1 \alpha$ and a reduction at higher concentration.

\section{CAMP-PKA in SDF-1 $\alpha$-linked P-CREB}

Since the experimental evidence indicates that SDF- $1 \alpha$ stimulation leads to increased P-CREB, and also shows a role for CRE-binding sites in the activation of Tac1/N0 (Fig. 1), we next performed studies to identify the candidate molecules upstream of P-CREB. The studies focused on CAMP-PKA pathway due to its involvement in Tacl activity in bone marrow stromal cells (Qian et al. 2001a). MCF12A was transfected with pGL3-Tac1/N0 and then stimulated with SDF- $1 \alpha$ at $50 \mathrm{ng} / \mathrm{ml}$ in the presence or absence of the cAMP inhibitor, cAMPS-Rp $(10 \mu \mathrm{M})$ or PKA inhibitor H-89 $(5 \mu \mathrm{M})$. The concentrations of inhibitors were determined in doseresponse curves (not shown). Interestingly, each inhibitor resulted in significant $(P<0.05)$ increase in luciferase activities (Fig. 2A). While this indicates that neither cAMPs nor PKAs are upstream mediators of P-CREB, it brings up an important observation that cAMP-PKA could cause exacerbated Tac1 activity.

\section{PI3K in SDF-1 $\alpha$-mediated activation of PPT-I/NO}

SDF-1 $\alpha$ activation of CXCR4 has been shown to involve $\mathrm{G} \alpha_{i}$, which has been reported to inhibit cAMP activation (Goichberg et al. 2006). Studies with cAMP and PKA inhibitors rule out these messengers as upstream mediators in the activation of Tac1/N0 (Fig. 2A). We therefore examined alternative pathways that could lead to P-CREB, which has been reported to occur through PI3K-AKT pathway (Du \& Montminy 1998, Perkinton et al. 2002). MCF12A was transfected with pGL3-Tac1/N0 and then stimulated with SDF-1 $\alpha$ at $50 \mathrm{ng} / \mathrm{ml}$ in the presence or absence of $5 \mu \mathrm{M}$ PI3K or AKT inhibitor. Inhibitor concentrations were determined in dose-response studies (not shown). While there was significant decrease $(P<0.05)$ in reporter gene activity with PI3K inhibitor, there was significant $(P<0 \cdot 05)$ increase in AKT inhibitor (Fig. 2B). This suggests the involvement of PI3K, but not AKT in the activation of Tac1/N0. Thus, the studies suggest that PI3K activation is upstream of activator of CREB.

\section{Mediators downstream of PI3K}

The results in Fig. 2B implicate PI3K as a mediator between SDF-1 $\alpha$ stimulation and phosphorylation of CREB. We propose PKC as a mediator since it has been shown to activate CREB through the MAPK cascade 
(Greco et al. 2006). We therefore examined secondary messengers downstream of PI3K in the activation of Tac1/N0 by selecting PKC, MAPK (p38), ERK, and JNK, based on their involvement in other studies (Perkinton et al. 2002). In general, PI3K activates PKC, which in turn activates Raf-1 (Takeda et al. 1999). The latter activates MEKK1/2 (Takeda et al. 1999). At this point, there are three potential targets of MEKK1/2 such as p38, ERK, and JNK (Kito et al. 2000). We first transfected MCF12A with pGL3-Tac1/N0 and then stimulated the transfectants with $50 \mathrm{ng} / \mathrm{ml} \mathrm{SDF}-1 \alpha$ in the presence or absence of PKC $(10 \mu \mathrm{M})$, ERK $(5 \mu \mathrm{M})$, JNK $(1 \mu \mathrm{M})$, or p38 $(1 \mu \mathrm{M})$ inhibitors. Their respective concentrations were determined in dose-response curves (not shown). After $16 \mathrm{~h}$, cell extracts were quantified for luciferase activity. The results showed significant $(P<0 \cdot 05)$ decrease in luciferase activities in the presence of PKC, ERK, and p38 (MAPK) inhibitors (Fig. 3A), and significant $(P<0.05)$ increase with JNK inhibitor (Fig. 3A). The results indicate the involvement of PKC-p38 and ERK activation, but not of JNK.

Functional assays in the presence of specific inhibitors indicated that Tacl activation involved PKCMEKK1/2-ERK1/2 signaling pathway. We therefore performed western analyses for the phosphorylated activators. MCF12A cells were stimulated with 20,50, or $100 \mathrm{ng} / \mathrm{ml} \mathrm{SDF}-1 \alpha$. Unstimulated cells served as controls. After $1 \mathrm{~h}$, cell fractions were analyzed by western analyses. PKC $\zeta$ has been implicated in ERK1/2 activation and was therefore selected as the focused isotype (Short et al. 2006). The results shown in Fig. 3B

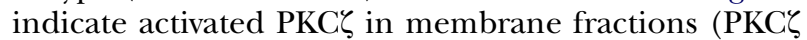
(M), row 1) whereas the inactivated forms are detected in the cytosolic fraction (PKCᄃ $(\mathrm{C})$, row 2$)$. When the bands in the top row are normalized with $\beta$-actin (Fig. 3B, last row), the level of activated PKC! is proportional to the SDF- $1 \alpha$ concentration. We next studied whether a similar relationship existed for the classical PKC isoform, PKC $\alpha$. Unlike PKC showed no change with SDF-1 $\alpha$ stimulation (Fig. 3B, rows 3 and 4). Since PKC MEKK1/2 and ERK1/2, we examined nuclear extracts for phospho-MEKK1/2 or ERK1/2 and found that phosphorylation of both was directly proportional to SDF-1 $\alpha$ concentration (Fig. 3B, second and third panels from the bottom). In summary, the studies in the section indicate activation of PKC $\zeta$, MEKK1/2, and ERK1/2 by SDF-1 $\alpha$ in MCF12A cells.

\section{G $\alpha$ subunit in SDF-1 $\alpha$ stimulation}

SDF- $1 \alpha$ stimulation led to the activation of CREB and ATF-1 in MCF12A (Fig. 1C). Furthermore, the CREbinding sites in Tacl are relevant to its stimulation (Fig. 1A). However, neither cAMPs nor PKAs appear to be mediators between SDF-1 $\alpha$ stimulation and the

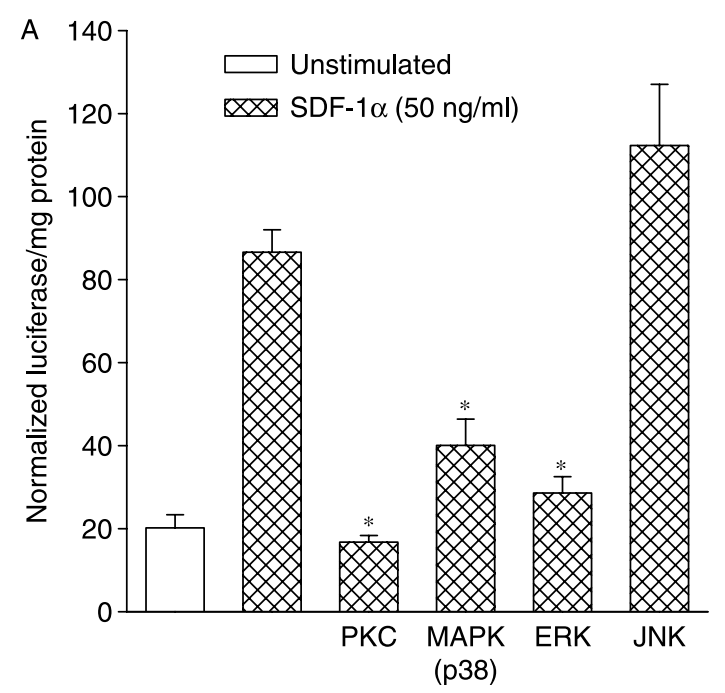

B
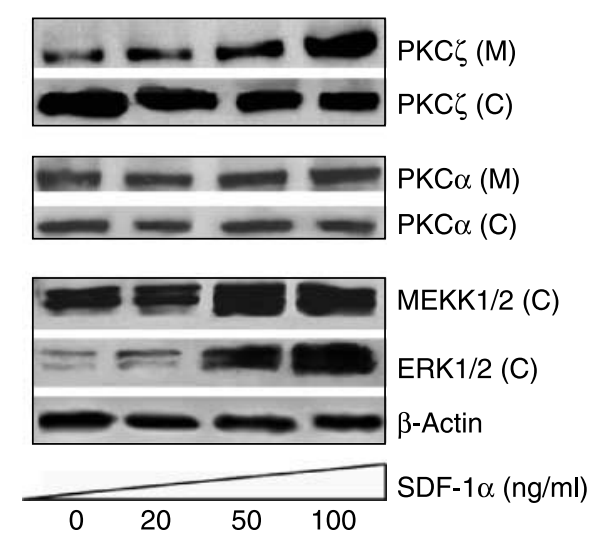

Figure 3 Role of PKC, p38, ERK, and JNK in the activation of PPT-I/N0. (A) MCF12A cells were transfected with pGL3-Tac1/N0 and the transfectants were stimulated with $50 \mathrm{ng} / \mathrm{ml} \mathrm{SDF-1} \alpha$ in the presence or absence of p38, ERK, or JNK inhibitors. The results are presented as mean RLU \pm s.D., $n=5$. ${ }^{\star} P<0.05$ versus transfectants without inhibitor. (B) MCF12A cells were unstimulated or stimulated with SDF- $1 \alpha$ at 20,50 , or $100 \mathrm{ng} / \mathrm{ml}$. After $1 \mathrm{~h}$, cytoplasmic $(C)$ and membrane $(M)$ extracts were analyzed by western blots with anti-PKC $\zeta$. Cytoplasmic extracts were analyzed for P-MEKK $1 / 2$ by western blots using an antibody that detect both phosphorylated and unphosphorylated MEKK1/2. Membranes were stripped and reprobed with anti-PKC $\alpha$ and

P-ERK1/2, and anti- $\beta$-actin. Representative blot is shown for four different experiments.

activation of the $5^{\prime}$ flanking region of Tac1 (Fig. 2A). Although SDF-1 $\alpha$ has been reported to activate CXCR-4 through $\mathrm{G} \alpha_{i}$ and $\mathrm{G} \alpha_{q}$ (Sotsios et al. 1999, Rochdi \& Parent 2003), it is unclear which $\mathrm{G} \alpha$ subunit is activated in our model system. We stimulated MCF12A with 50 or $100 \mathrm{ng} / \mathrm{ml} \mathrm{SDF}-1 \alpha$. After $30 \mathrm{~min}, 1 \mathrm{~h}$, and $3 \mathrm{~h}$, cell extracts were prepared and analyzed for activated $\mathrm{G} \alpha$ protein subunits by western blot. The data, representative of four blots, showed undetectable $\mathrm{G} \alpha_{\mathrm{s}}$ (Fig. 4A, third row from the bottom). Since $\mathrm{G} \alpha_{\mathrm{s}}$ has been shown to activate cAMP and PKA, the observation correlates 
A

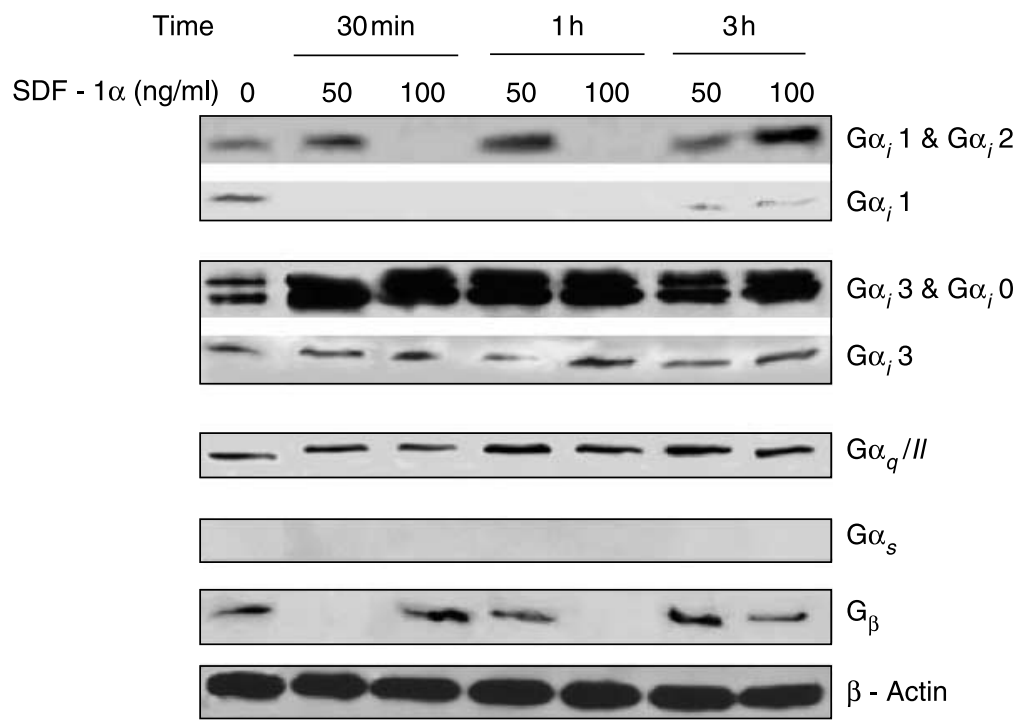

B
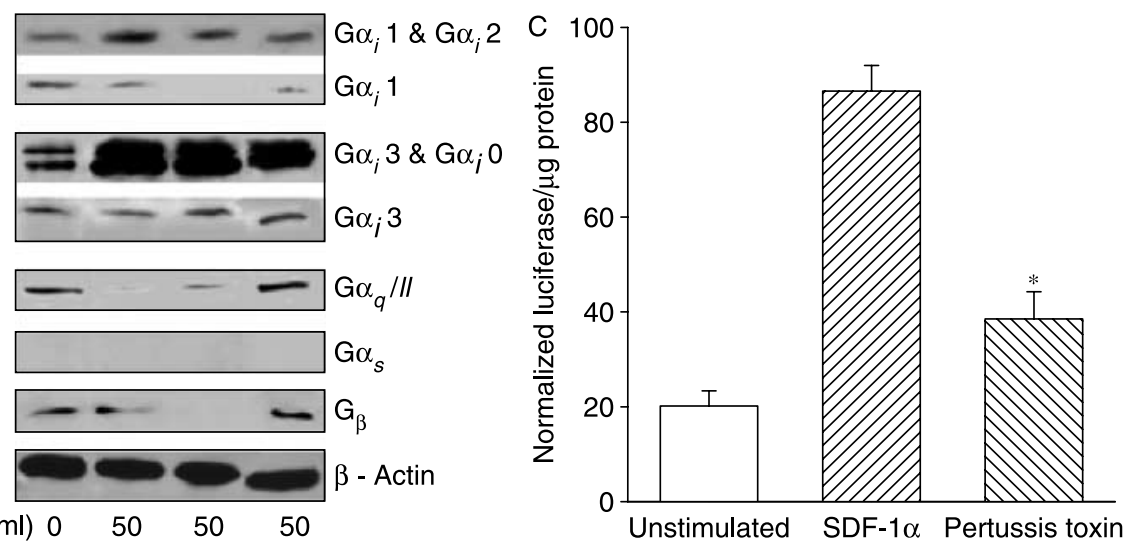

SDF-1 $\alpha(\mathrm{ng} / \mathrm{ml}) \quad 0 \quad 50 \quad 50 \quad 50$

Pertussis toxin - $\quad+\quad+$

LY294002 - $+\quad-\quad-$

Figure 4 Role of activated G-proteins in MCF12A cells stimulated SDF-1 $\alpha$. (A) MCF12A cells were unstimulated or stimulated with SDF-1 $\alpha$ (50 or $100 \mathrm{ng} / \mathrm{ml})$. At different times, whole cell extracts were analyzed by western blots with anti-G $\alpha_{i} 1$, anti-G $\alpha_{i} 1$ and 2, anti-G $\alpha_{j} 3$, anti-G $\alpha_{j} 3$ and $\mathrm{G} \alpha_{0}$, anti-G $\alpha_{q / 11}$, anti$\mathrm{G} \alpha_{s}$, anti-G $\beta$, and anti- $\beta$-actin. Multiple probings were done by consecutively stripping and reprobing of membranes. (B) MCF12A cells were unstimulated or stimulated with $50 \mathrm{ng} / \mathrm{ml} \mathrm{SDF-1 \alpha}$ in the presence or absence of LY294002 or pertussis toxin. After $3 \mathrm{~h}$, extracts were analyzed by western blot with anti-G $\alpha_{i} 1$, anti-G $\alpha_{j} 1$ and $\mathrm{G} \alpha_{i} 2$, anti-G $\alpha_{j} 3$, anti-G $\alpha_{j} 3$ and $\mathrm{G} \alpha_{0}$, anti-G $\alpha_{\alpha / 11}$, anti-G $\alpha_{s}$, anti-G $\beta$, and anti- $\beta$-actin.

Membranes were stripped and reprobed consecutively. (C) MCF12A was transiently transfected with pGL3-

Tac1/N0. After $16 \mathrm{~h}$, transfectants were stimulated with $50 \mathrm{ng} / \mathrm{ml} \mathrm{SDF}-1 \alpha$ and $/$ or $100 \mathrm{ng} / \mathrm{ml}$ pertussis toxin.

with the lack of cAMP-PKA activation (Fig. 2A). Interestingly, $\mathrm{G} \alpha_{i} 1$ became undetectable following stimulation with $50 \mathrm{ng} / \mathrm{ml}$ but increased after $3 \mathrm{~h}$ (Fig. 4A, second row). If the bands for $\mathrm{G} \alpha_{i} 1$ are subtracted from those for $\mathrm{G} \alpha_{i} 1 / \mathrm{G} \alpha_{i} 2$ (Fig. 4A, top row), it could be deduced that $\mathrm{G} \alpha_{i} 2$ is increased at $50 \mathrm{ng} / \mathrm{ml}$ up to $3 \mathrm{~h}$. This increase corresponds to the enhanced activity of Tac1/N0 at $50 \mathrm{ng} / \mathrm{ml}$ SDF- $1 \alpha$ (Fig. 1A). $\mathrm{G} \alpha_{i} 3$ and $\mathrm{G} \alpha_{q}$ were unchanged in unstimulated and stimulated MCF12A (Fig. 4A, rows 3-5).

\section{Role of $\mathrm{G}_{i}$ subunits in SDF-1 $\alpha$-mediated activation of PPT-I/NO}

The experimental evidence suggests that $\mathrm{G} \alpha_{i} 2$ could be a key factor following stimulation of MCF12A with SDF-1 $\alpha$ (Fig. 4A). To ascertain that its activation is not an artifact, we repeated the experiments described for Fig. $4 \mathrm{~A}$ in the presence or absence of pertussis toxin, which is an inhibitor of $\mathrm{G} \alpha_{i}$. The results showed that undetectable $\mathrm{G} \alpha_{i} 1$ in cells stimulated in the presence of 
pertussis toxin (Fig. 4B, second row, lane 3 ). When the normalized densities of $\mathrm{G} \alpha_{i} 1$ are subtracted from $\mathrm{G} \alpha_{i} 1$ and $\mathrm{G} \alpha_{i} 2$ (Fig. 4B, rows 1 and 2), there was a fivefold reduction in $\mathrm{G} \alpha_{i} 2$ (Fig. $4 \mathrm{~B}$, row 1 , lane 3 ). This indicates that SDF- $1 \alpha$ activates $G \alpha_{i} 2$ which is partially sensitive to pertussis toxin.

We next determined which G-protein subunit was expressed if we block downstream PI3K. To this end, we repeated the experiments described for Fig. 4A, in the presence or absence of the PI3K inhibitor, LY294002. The results showed a slight increase in the band density for $\mathrm{G}_{i} 2$ (Fig. 4B, lanes 1 and 2). This increase is consistent with the signaling pathway being blocked to cause an accumulation of activated $\mathrm{G} \alpha_{i} 2$. The slight accumulation of $\mathrm{G} \alpha_{i} 2$ is not an artifact for all G-protein subunits since we observed a reduction in $\mathrm{G} \alpha_{q}$ in the presence of both LY294002 and pertussis toxin (Fig. 4B, row 5). A point worth mentioning is that downregulation of $\mathrm{G} \alpha_{q}$, both in the presence of pertussis toxin and accumulation in the presence of LY294002, signifies that it is not the major signaling molecule but rather $\mathrm{G} \alpha_{i} 2$ could be the predominant subunit.

The next set of studies determined whether the loss in $\mathrm{G} \alpha_{i}$ protein when cells were stimulated in the presence of pertussis toxin (Fig. 4B, rows 1 and 2) affected the activity of Tac1/N0. To address this question, MCF12A cells were transfected with Tac1/N0. After $16 \mathrm{~h}$, the transfectants were stimulated with $50 \mathrm{ng} / \mathrm{ml} \mathrm{SDF}-1 \alpha$, in the presence or absence of $100 \mathrm{ng} / \mathrm{ml}$ pertussis toxin. At $16 \mathrm{~h}$ of stimulation, luciferase activities were quantitated and the results showed significant downregulation, thus linking pertussis toxin-sensitive G-protein subunits with the induction of Tac1/N0.

\section{Discussion}

This study dissects the mechanism by which SDF-1 $\alpha$ activates the $5^{\prime}$ flanking region of Tac1 in non-tumorigenic MCF12A. The role of SDF-1 $\alpha$ on the regulation of Tacl is complex, depending on the concentration of SDF- $1 \alpha$ and the activator sequences within Tac1. SDF-1 $\alpha$ induces the activation of the $5^{\prime}$ flanking region of Tacl in a dose-dependent manner, only if the upstream sequence of exon 1 is absent (Corcoran \& Rameshwar 2007). While relatively low concentrations $(20-50 \mathrm{ng} / \mathrm{ml})$ of SDF- $1 \alpha$ stimulate the $5^{\prime}$ flanking region of Tac1 and induce its expression, higher concentration $(100 \mathrm{ng} / \mathrm{ml})$ mediates inhibition (Corcoran \& Rameshwar 2007). In the absence of exon $1(\mathrm{Tac} 1 / \mathrm{N} 0)$, there is a dose-dependent effect between SDF-1 $\alpha$ and Tac1 activity (Corcoran et al. 2007). $\mathrm{NF} \kappa \mathrm{B}$-binding region found within exon 1 of the Tac1 gene has been shown to mediate gene repression at high concentrations of SDF-1 $\alpha$ (Corcoran \& Rameshwar 2007). Since this study sought to determine the stimulatory pathway of SDF-1 $\alpha$ in Tac1 activation, we focused on the PPT-I/N0 gene construct.

The CRE-binding regions of Tacl are relevant to gene activation in bone marrow cells (Qian et al. 2001a). In this report, overexpression of the negative regulator of CRE-binding proteins, ICER inhibited the activation of Tac1/N0 despite stimulation with SDF-1 $\alpha$ (Fig. 1A). This indicates a role for CRE region within Tac1 in SDF$1 \alpha$-mediated stimulation of PPT-I/N0. These studies were supported by functional assays with PPT-I/N0 in which the CRE sites were mutated (Fig. 1B). Interestingly, mutation of CRE II showed a trend toward Tac1/N0 activation, independent of SDF-1 $\alpha$ (Fig. 1B). On the other hand, double mutation of the CRE region showed a decrease in baseline luciferase activity as compared with wild-type CRE (Fig. 1B). However, despite the double mutations, we observed an increase in luciferase activity upon SDF-1 $\alpha$ stimulation (Fig. 1B, extreme right hatched bar). Other transcription factorbinding sites in Tac1/N0 might answer this unexpected increase in luciferase with the double mutants. Ongoing studies have found a stimulatory role for an overlapping Smad (small mothers against decapentaplegic) site following CRE II mutation (unpublished).

Computer analysis of Tac1/N0 for transcription factor motifs has indicated consensus regions for multiple factors, including a YY1 site $\sim 15$ bp upstream of CRE I. In addition, we also observed a SMAD4- and RESTbinding sites at 20 and $50 \mathrm{bp}$ upstream of the CRE II site respectively. The transcription factors, especially YY1 and SMAD4, would be difficult to access by their respective binding sites when CRE-binding sites are occupied. While we have shown by electrophoretic mobility shift assay that SMAD4 is an authentic binding site (unpublished), similar functional analyses have not been studied for the YYl consensus sequence. Thus, the increase in luciferase at baseline and in stimulated cells with CRE double mutants might be explained by the newly exposed YY1 and SMAD sites. This is further supported by the clear repression of SDF- $1 \alpha$ activation of Tac1 by ICER, which competes for binding to the CRE site (Fig. 1A; Rosenberg et al. 2002). Single mutants also inhibited Tac1/N0 activation by SDF-1 $\alpha$ (Fig. 1B).

Cytokines, such as IL- $1 \alpha$, activate Tac1 via the cAMP pathway (Qian et al. 2001a). CXCR4 generally signals via $\mathrm{G} \alpha_{i}$ with concomitant inhibition of the cAMP activator, $\mathrm{G} \alpha_{s}$. Other studies have shown that an accumulation of cAMP could negatively affect PI3K but nonetheless stimulate molecules downstream of PI3K, including PKC (Goichberg et al. 2006). Thus, cAMP while inhibiting PI3K could activate PKC through Rap1-GTP (Goichberg et al. 2006). In this report, we have ruled out the involvement of cAMP in Tacl/N0 activation (Fig. 2A). Rather we showed the involvement of PKC, MAPK, and ERK (Fig. 3A). 
Indeed, SDF-1 $\alpha$ activates PI3K by the activation of $\mathrm{G} \alpha_{i} 2$ (Figs 2B and 4). Downstream of PI3K is PKCᄃ followed by MEKK1/2 - ERK1/2 (Figs 3 and 5). Although MEKK1/2 was determined by western analysis for its phosphorylated forms, and not by function, this sequential was deduced, in combinations with the investigations for cAMP-PKA pathway (Figs 2 and 3). The reported findings on SDF- $1 \alpha$ signaling through PI3K-PKC-MAPK pathway to activate Tac1/N0 are consistent with the literature pertaining to pathways in brain (Petit et al. 2005).

The present report has physiological relevance to breast cancer. Both SDF- $1 \alpha$ and Tac1 expressions are altered in breast cancer cells as they traverse the bone marrow cavity toward the region of high SDF-1 $\alpha$ levels (Rao et al. 2004, Kucia et al. 2005). Thus, an understanding of the relationship between SDF-1 $\alpha$ and Tac1 expression in non-tumorigenic cells, as reported in this study, could be extrapolated to an understanding bone marrow micrometastasis of breast and, perhaps other cancers. Based on our study of the SDF-1 $\alpha /$ Tac1 pathway in the non-tumorigenic model (Fig. 5) and previous report that breast cancer cells adapt a quiescent phenotype in bone marrow, we propose that as cancer cells enter bone marrow they are likely to follow the pathways shown in this study with non-tumorigenic cells (Fig. 5). As cancer cells move toward the endosteum, where the SDF- $1 \alpha$ level is high in the stromal cells and low in the integrating breast cancer cells (Moharita et al. 2006), Tac1 expression would be consistent with the combined levels of Tac1 and the microenvironment, where cytokines such as TGF- $\beta 1$ levels are increased in the breast cancer cells (Oh et al. 2004). The various changes in both breast cancer and bone marrow-resident cells ultimately lead to a quiescent

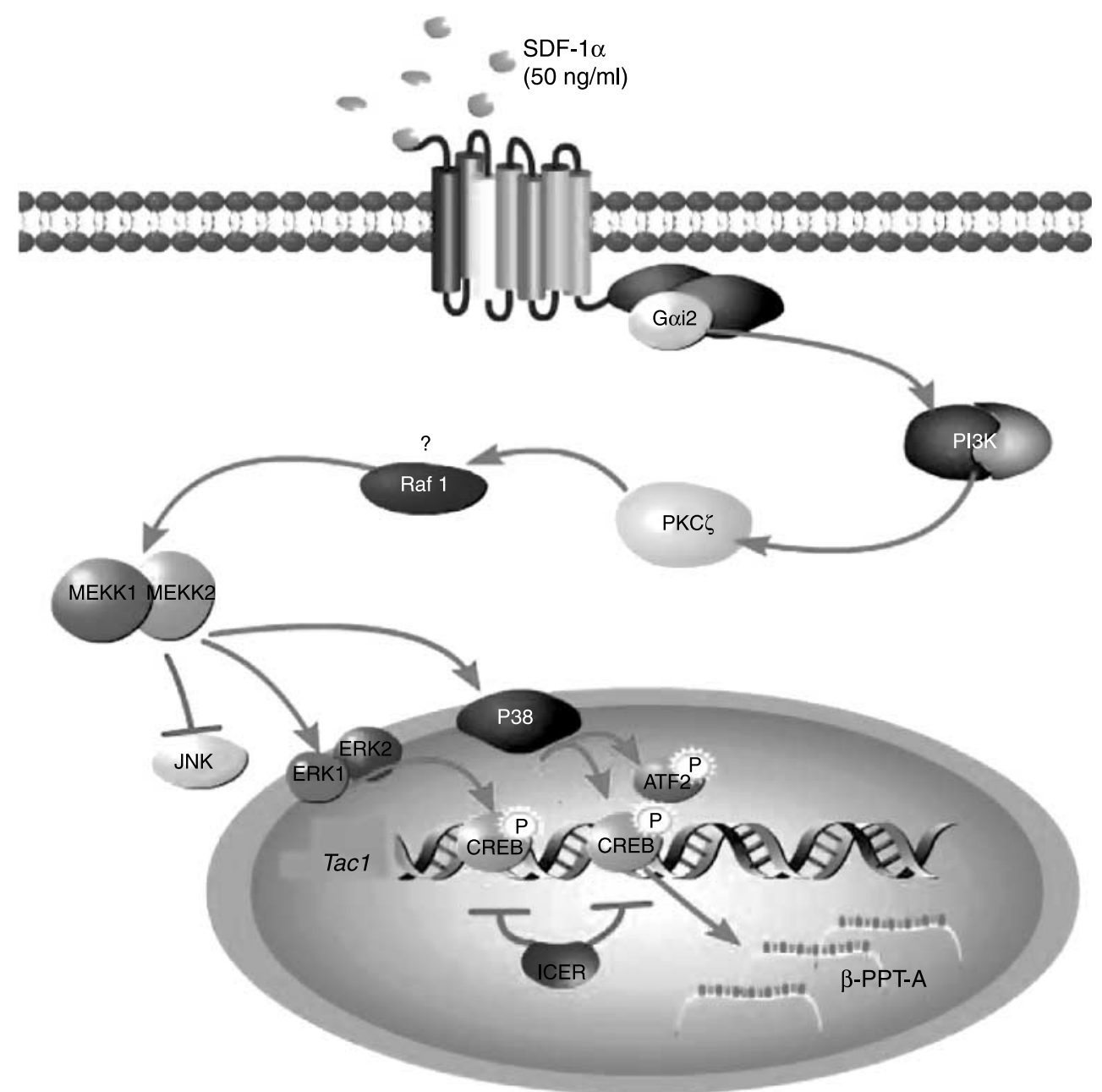

Figure 5 Summary shown for SDF-1 $\alpha$-mediated induction of Tac1. Shown is the intracellular pathway described in this report following the stimulation of MCF12A by SDF- $1 \alpha$ at $50 \mathrm{ng} / \mathrm{ml}$ to the activation of Tac1. SDF- $1 \alpha$ activates $\mathrm{G} \alpha_{\mathrm{i}}$, which in turn activates PKC $\zeta-M E K K 1 / 2-E R K 1 / 2$ (Fig. $3 A$ ) resulting in the phosphorylation of CREB, which is repressed by ICER (Figs 1 and 2). Phosphorylation of CREB leads to the activation of the $5^{\prime}$ flanking region of Tac1. 
phenotype of the breast cancer cells, without affecting hematopoiesis (Rao et al. 2004). Tacl appears to be necessary for endothelial-mesenchymal-stromal transition, and efficient entry of breast cancer cells into the bone marrow, in particular in regions close to the endosteum (Rao et al. 2004). These studies will require in vivo models to further evaluate how the SDF- $1 \alpha$ gradient in bone marrow and the SDF-1 $\alpha /$ Tac1 pathway in the non-tumorigenic model could relate to breast metastasis. However, we propose that the regulation of Tac 1 by SDF-1 $\alpha$ is amenable to breast cancer cells as they move into the bone marrow through a gradient change in SDF-1 $\alpha$.

\section{Acknowledgements}

This work was supported by the grant awarded by the Department of Defense and UH-New Jersey Medical School Cancer Center. The authors declare that there is no conflict of interest that would prejudice the impartiality of this scientific work.

\section{References}

Aalto Y, Forsgren S, Kjorell U, Bergh J, Franzen L \& Henriksson R 1998 Enhanced expression of neuropeptides in human breast cancer cell lines following irradiation. Peptides 19 231-239.

Bandari PS, Qian J, Oh HS, Potian JA, Yehia G, Harrison JS \& Rameshwar P 2003 Crosstalk between neurokinin receptors is relevant to hematopoietic regulation: cloning and characterization of neurokinin-2 promoter. Journal of Neuroimmunology 138 65-75.

Bellucci F, Carini F, Catalani C, Cucchi P, Lecci A, Meini S, Patacchini R, Quartara L, Ricci R, Tramontana M et al. 2002 Pharmacological profile of the novel mammalian tachykinin, hemokinin 1. British Journal of Pharmacology 135 266-274.

Bigioni M, Benzo A, Irrissuto C, Maggi CA \& Goso C 2005 Role of NK-1 and NK-2 tachykinin receptor antagonism on the growth of human breast carcinoma cell line MDA-MB-231. Anticancer Drugs 16 1083-1089.

Castro TA, Cohen MC \& Rameshwar P 2005 The expression of neurokinin-1 and preprotachykinin-1 in breast cancer cells depends on the relative degree of invasive and metastatic potential. Clinical and Experimental Metastasis 22 621-628.

Ceradini DJ, Kulkarni AR, Callaghan MJ, Tepper OM, Bastidas N, Kleinman ME, Capla JM, Galiano RD, Levine JP \& Gurtner GC 2004 Progenitor cell trafficking is regulated by hypoxic gradients through HIF-1 induction of SDF-1. Nature Medicine 10 858-864.

Corcoran KE \& Rameshwar P 2007 Nuclear factor- $\kappa$ B accounts for the repressor effects of high stromal cell-derived factor-1 $\alpha$ levels on Tac1 expression in nontumorigenic breast cells. Molecular Cancer Research 5 373-381.

Corcoran KE, Patel N \& Rameshwar P 2007 Stromal derived growth factor- $1 \alpha$ : another mediator in neural-emerging immune system through Tac1 expression in bone marrow stromal cells. Journal of Immunology 178 2075-2082.

De La Luz Sierra M, Yang F, Narazaki M, Salvucci O, Davis D, Yarchoan R, Zhang HH, Fales H \& Tosato G 2004 Differential processing of stromal-derived factor- $1 \alpha$ and stromal-derived factor- $1 \beta$ explains functional diversity. Blood 103 2452-2459.

Du K \& Montminy M 1998 CREB is a regulatory target for the protein kinase Akt/PKB. Journal of Biological Chemistry 273 32377-32379.
Fan TP, Hu DE, Guard S, Gresham GA \& Watling KJ 1993 Stimulation of angiogenesis by substance $\mathrm{P}$ and interleukin- 1 in the rat and its inhibition by NK1 or interleukin-1 receptor antagonists. British Journal of Pharmacology 110 43-49.

Ganju RK, Brubaker SA, Meyer J, Dutt P, Yang Y, Qin S, Newman W \& Groopman JE 1998 The alpha-chemokine, stromal cell-derived factor- $1 \alpha$, binds to the transmembrane G-protein-coupled CXCR-4 receptor and activates multiple signal transduction pathways. Journal of Biological Chemistry 273 23169-23175.

Gazitt Y 2004 Homing and mobilization of hematopoietic stem cells and hematopoietic cancer cells are mirror image processes, utilizing similar signaling pathways and occurring concurrently: circulating cancer cells constitute an ideal target for concurrent treatment with chemotherapy and anti lineage-specific antibodies. Leukemia 18 1-10.

Goichberg P, Kalinkovich A, Borodovsky N, Tesio M, Petit I, Nagler A, Hardan I \& Lapidot T 2006 cAMP-induced PKC $\zeta$ activation increases functional CXCR4 expression on human CD34+ hematopoietic progenitors. Blood 107 870-879.

Greco SJ, Corcoran KE, Cho KJ \& Rameshwar P 2004 Tachykinins in the emerging immune system: relevance to bone marrow homeostasis and maintenance of hematopoietic stem cells. Frontiers of Bioscience 9 1782-1793.

Greco S, Storelli C \& Marsigliante S 2006 Protein kinase C (PKC) $-\delta /-\varepsilon$ mediate the PKC/Akt-dependent phosphorylation of extracellular signal-regulated kinases 1 and 2 in MCF-7 cells stimulated by bradykinin. Journal of Endocrinology 188 79-89.

Juarez J, Bendall L \& Bradstock K 2004 Chemokines and their receptors as therapeutic targets: the role of the SDF-1/CXCR4 axis. Current Pharmaceutical Design 95 2505-2513.

Jung Y, Wang J, Schneider A, Sun YX, Koh-Paige AJ, Osman NI, McCauley LK \& Taichman RS 2006 Regulation of SDF-1 (CXCL12) production by osteoblasts; a possible mechanism for stem cell homing. Bone 38 497-508.

Kang HS, Trzaska KA, Corcoran K, Chang VT \& Rameshwar P 2004 Neurokinin receptors: relevance to the emerging immune system. Archivum Immunologiae et Therapiae Experimentalis 52 338-347.

Kato M, Kitayama J, Kazama S \& Nagawa H 2003 Expression pattern of CXC chemokine receptor-4 is correlated with lymph node metastasis in human invasive ductal carcinoma. Breast Cancer Research 5 R144-R150.

Kito H, Chen EL, Wang X, Ikeda M, Azuma N, Nakajima N, Gahtan V \& Sumpio BE 2000 Role of mitogen-activated protein kinases in pulmonary endothelial cells exposed to cyclic strain. Journal of Applied Physiology 89 2391-2400.

Kucia M, Reca R, Miekus K, Wanzeck J, Wojakowski W, JanowskaWieczorek A, Ratajczak J \& Ratajczak MZ 2005 Trafficking of normal stem cells and metastasis of cancer stem cells involve similar mechanisms: pivotal role of the SDF-1-CXCR4 axis. Stem Cells $\mathbf{2 3}$ 879-894.

Lapidot T, Dar A \& Kollet O 2005 How do stem cells find their way home? Blood 106 1901-1910.

Maloof PB, Joshi DD, Qian J, Gascon P, Singh D \& Rameshwar P 2001 Induction of preprotachykinin-I and neurokinin-1 by adrenocorticotropin and prolactin. Implication for neuroendocrine-immunehematopoietic axis. Journal of Neuroimmunology 112 188-196.

Moharita A, Harrison J \& Rameshwar P 2004 Neurokinin receptors and subtypes as potential targets in breast cancer: relevance to bone marrow metastasis. Drug Design Reviews - Online 1 297-302.

Moharita AL, Taborga M, Corcoran KE, Bryan M, Patel PS \& Rameshwar P 2006 SDF-1 $\alpha$ regulation in breast cancer cells contacting bone marrow stroma is critical for normal hematopoiesis. Blood 108 3245-3252.

Mori T, Doi R, Koizumi M, Toyoda E, Ito D, Kami K, Masui T, Fujimoto K, Tamamura H, Hiramatsu K et al. 2004 CXCR4 antagonist inhibits stromal cell-derived factor 1-induced migration and invasion of human pancreatic cancer. Molecular Cancer Therapeutics 3 29-37. 
Muller A, Homey B, Soto H, Ge N, Catron D, Buchanan ME, McClanahan T, Murphy E, Yuan W, Wagner SN et al. 2001 Involvement of chemokine receptors in breast cancer metastasis. Nature 410 50-56.

Oh HS, Moharita A, Potian JG, Whitehead IP, Livingston JC, Castro TA, Patel PS \& Rameshwar P 2004 Bone marrow stroma influences transforming growth factor- $\beta$ production in breast cancer cells to regulate c-myc activation of the preprotachykinin-I gene in breast cancer cells. Cancer Research 64 6327-6336.

Palesh O, Butler LD, Koopman C, Giese-Davis J, Carlson R \& Spiegel D 2007 Stress history and breast cancer recurrence. Journal of Psychosomatic Research 63 233-239.

Perkinton MS, Ip JK, Wood GL, Crossthwaite AJ \& Williams RJ 2002 Phosphatidylinositol 3-kinase is a central mediator of NMDA receptor signalling to MAP kinase (Erk1/2), Akt/PKB and CREB in striatal neurones. Journal of Neurochemistry 80 239-254.

Petit I, Goichberg P, Spiegel A, Peled A, Brodie C, Seger R, Nagler A, Alon R \& Lapidot T 2005 Atypical PKC- $\zeta$ regulates SDF-1-mediated migration and development of human CD34+ progenitor cells. Journal of Clinical Investigation 115 168-176.

Qian J, Yehia G, Molina CA, Fernandes A, Donnelly RJ, Anjaria DJ, Gascon P \& Rameshwar P 2001 $a$ Cloning of human preprotachykinin-I promoter and the role of cyclic adenosine 5?-monophosphate response elements in its expression by IL-1 and stem cell factor Journal of Immunology 166 2553-2561.

Qian J, Ramroop K, McLeod A, Bandari P, Livingston DH, Harrison JS \& Rameshwar P $2001 b$ Induction of hypoxia-inducible factor- $1 \alpha$ and activation of caspase-3 in hypoxia-reoxygenated bone marrow stroma is negatively regulated by the delayed production of substance P. Journal of Immunology 167 4600-4608.

Rameshwar P \& Gascon P 1996 Induction of negative hematopoietic regulators by neurokinin-A in bone marrow stroma. Blood 88 98-106.

Rao G, Patel PS, Idler SP, Maloof P, Gascon P, Potian JA \& Rameshwar P 2004 Facilitating role of preprotachykinin-I gene in the integration of breast cancer cells within the stromal compartment of the bone marrow: a model of early cancer progression. Cancer Research 64 2874-2881.

Rochdi MD \& Parent JL $2003 \mathrm{G} \alpha_{\mathrm{q}}$-coupled receptor internalization specifically induced by $\mathrm{G} \alpha_{\mathrm{q}}$ signaling. Regulation by EBP50. Journal of Biological Chemistry 278 17827-17837.

Roland J, Murphy BJ, Ahr B, Robert-Hebmann V, Delauzun V, Nye KE, Devaux C \& Biard-Piechaczyk M 2003 Role of the intracellular domains of CXCR4 in SDF-1-mediated signaling. Blood 101 399-406.
Rosenberg D, Groussin L, Jullian E, Perlemoine K, Bertagna X \& Bertherat J 2002 Role of the PKA-regulated transcription factor CREB in development and tumorigenesis of endocrine tissues. Annals of the New York Academy of Sciences 968 65-74.

Servillo G, la Fazia MA \& Sassone-Corsi P 2002 Coupling cAMP signaling to transcription in the liver: pivotal role of CREB and CREM. Experimental Cell Research 275 143-154.

Short MD, Fox SM, Lam CF, Stenmark KR \& Das M 2006 Protein kinase C $\zeta$ attenuates hypoxia-induced proliferation of fibroblasts by regulating MAP kinase phosphatase-1 expression. Molecular Biology of the Cell 17 1995-2008.

Singh D, Joshi DD, Hameed M, Qian J, Gascon P, Maloof PB, Mosenthal A \& Rameshwar P 2000 Increased expression of preprotachykinin-I and neurokinin receptors in human breast cancer cells: implications for bone marrow metastasis. PNAS $\mathbf{9 7}$ 388-393.

Smith MCP, Luker KE, Garbow JR, Prior JL, Jackson E, Piwnica-Worms D \& Luker GD 2004 CXCR4 regulates growth of both primary and metastatic breast cancer. Cancer Research 64 8604-8612.

Sotsios Y, Whittaker GC, Westwick J \& Ward SG 1999 The CXC chemokine stromal cell-derived factor activates a Gi-coupled phosphoinositide 3-kinase in T lymphocytes. Journal of Immunology $1635954-5963$.

Takeda H, Matozaki T, Takada T, Noguchi T, Yamao T, Tsuda M, Fukunaga K, Ochi F, Inagaki K \& Kasuga M 1999 PI3-kinase $\gamma$ and protein kinase $\mathrm{C}-\zeta$ mediate RAS-independent activation of MAP kinase by a $\mathrm{G}_{\mathrm{i}}$ protein-coupled receptor. EMBO Journal 18 386-395.

Wang JF, Park IW \& Groopman JE 2000 Stromal cell-derived factor- $1 \alpha$ stimulates tyrosine phosphorylation of multiple focal adhesion proteins and induces migration of hematopoietic progenitor cells: roles of phosphoinositide-3 kinase and protein kinase C. Blood $\mathbf{9 5}$ 2505-2513.

Ziemssen T \& Kern S 2007 Psychoneuroimmunology - cross-talk between the immune and nervous systems. Journal of Neurology 254 (Suppl 2) 8-11.

Received in final form 28 October 2007

Accepted 2 January 2008

Made available online as an Accepted Preprint

2 January 2008 